\begin{abstract}
Iranica
Abstracta Iranica Revue bibliographique pour le domaine irano-aryen

Volume 34-35-36 | 2017

Comptes rendus des publications de 2011-2013
\end{abstract}

\title{
Hemming Jorgensen. Ice Houses of Iran Where - How - Why
}

\section{Rémy Boucharlat}

\section{(2) OpenEdition}

\section{Journals}

\section{Édition électronique}

URL : http://journals.openedition.org/abstractairanica/41355

DOI : 10.4000/abstractairanica.41355

ISSN : 1961-960X

Éditeur :

CNRS (UMR 7528 Mondes iraniens et indiens), Éditions de l'IFRI

Référence électronique

Rémy Boucharlat, "Hemming Jorgensen. Ice Houses of Iran Where - How - Why », Abstracta Iranica [En ligne], Volume 34-35-36 | 2017, document 1, mis en ligne le 15 juillet 2016, consulté le 02 octobre 2020. URL : http://journals.openedition.org/abstractairanica/41355 ; DOI : https://doi.org/10.4000/ abstractairanica.41355

Ce document a été généré automatiquement le 2 octobre 2020.

Tous droits réservés 


\title{
Hemming Jorgensen. Ice Houses of Iran Where - How - Why
}

\author{
Rémy Boucharlat
}

\section{RÉFÉRENCE}

Hemming Jorgensen. Ice Houses of Iran Where - How - Why. Costa Mesa, Mazda, 2012, 240

p., bibliographie, index, 112 figures et photos coul. (Bibliotheca Iranica, Archaeology,

Art and Architecture Series, No. 2)

1 Ce livre est la publication de la thèse de l'A., ingénieur civil danois, qui a travaillé dans divers pays du monde dont l'Iran. C'est seulement après sa carrière professionnelle qu'il a entrepris cette recherche en 2007 , se souvenant de sa découverte des glacières iraniennes en 1966. C'est un parcours qui rappelle celui de Henri Goblot, géologue français, qui naguère commença à étudier les qanāts en 1960 après un séjour de vingt ans en Iran. Le rapprochement vaut aussi pour l'objet de ce livre, puisque nombre de glacières sont alimentées par des qanāts.

2 H.M. présente d'abord (chap. 1) l'état de la recherche et de l'inventaire patrimonial, avec un premier résultat important: la liste de l'ICHTO de 56 glacières (yaHčāl) est portée à 129 au terme de l'enquête. Ce sont des fosses cylindriques, le plus souvent en partie enterrée sur plusieurs mètres, dont les parois sont en sārūj (mortier de chaux). C'est la partie qui contiendra la glace. La couverture peut être au niveau du sol, en briques crues, mais très souvent elle s'élève sur la fosse en forme de dôme conique ou ellipsoïdal qui les fait ressembler aux citernes (āb-anbār). L'absence totale de tour à vent (bādgīr) dans les glacières est trait distinctif entre les deux constructions à dôme. À côté de la plupart des dômes est installé un mur haut de plusieurs mètres, face au sud, projetant une ombre sur un bassin de plusieurs dizaines de mètres de long, mais très peu profond dans lequel est mise régulièrement en hiver une mince couche d'eau qui se transformera en glace; dès que celle-ci est formée, elle est cassée au pic, collectée et mise dans la fosse ; elle constitue une réserve de glace jusqu'à l'été. Le chap. 2 donne le 
contexte et l'origine de ces monuments d'architecture traditionnelle. Si le principe de la glacière est très ancien en Orient (autour de $2000 \mathrm{av}$. J.-C. en Mésopotamie), rien de permet de faire remonter les constructions à dôme au-delà des premières mentions de voyageurs au XVII ${ }^{\mathrm{e}}$ siècle. On trouve ces glacières principalement dans le monde rural.

$3 \quad$ H.J. présente son travail d'enquête au chap. 3, bien conscient du caractère préliminaire de celle-ci et de la méthode, puis la typologie et la répartition dans le pays (chap. 4). Les chapitres suivants 5-6 décrivent les monuments. Cette présentation est selon la forme, la proximité d'un village, caravansérail ou fort, et par province (Téhéran, Markazī, Kermān, Yazd, Eșfahān, Semnān, Hơōāān Raḍavī, Ḩorāsān Jonūbī), qui sont très majoritairement, on s'en doute, celles de la bordure du désert central). Le chap. 7 traite des aspects techniques des glacières et offrent des données chiffrées sur celles-ci. Dans le dernier chapitre, l'A. expose l'état de ces monuments et les mesures prises pour les conserver, que ce soit par les autorités du patrimoine, depuis 1970, mais longtemps de façon très incomplètes, ou parfois, à partir d'initiatives privées et locales.

4 C'est un travail de pionnier qu'a réalisé H.J., car bien peu d'auteurs antérieurs n'ont traité la question, à l'exception d'un chapitre de E. Beazley \& M. Harverson, Living with the Desert, 1982, p. 49-56, ainsi que deux ouvrages en persan sur l'architecture vernaculaire en Iran. Son ouvrage, qui devrait être traduit en persan, incitera sûrement les autorités iraniennes nationales et provinciales à répertorier plus complètement, étudier et conserver ces témoins de l'architecture vernaculaire dont beaucoup sont déjà très dégradés. Après ce livre, il était logique que l'A. soit sollicité pour rédiger l'entrée yaǩčăl pour l'Encyclopaedia Iranica (http://www.iranicaonline.org/articles/ yakcal, 2012).

\section{AUTEURS}

\section{RÉMY BOUCHARLAT}

CNRS, Lyon 